\title{
CONSTRUINDO UMA GROUNDED THEORY SOBRE FAMÍLIAS BRASILEIRAS E CONSUMOS DE ANÚNCIOS COM CASAIS LGBT: INQUIETAÇÕES METODOLÓGICAS E INTERSECCIONALIDADE
}

\author{
Constructing Grounded Theory on Brazilian families and \\ ad consumption with same-sex couples: methodological \\ concerns and intersectionality
}

Construyendo una Grounded Theory sobre las familias brasileñas y el consumo de anuncios con parejas LGBT: preocupaciones metodológicas e interseccionalidad

\author{
Francisco Leite \\ Universidade de São Paulo, São Paulo, Brasil \\ Doutor em Ciências da Comunicação pela ECA-USP. Professor colaborador e Pós-doutorando \\ Fapesp (Proc. 2017/08319-7) na ECA-USP. Autor de Publicidade contraintuitiva: inovação no uso de \\ estereótipos na comunicação (Appris, 2014), As brasileiras e a publicidade contraintuitiva (Alameda/ \\ Fapesp, 2018) e coorganizador de Publicidade Antirracista (ECA-USP, 2019), obra finalista do Prêmio \\ Jabuti 2020, entre outras publicações \\ E-mail:fcoleite@usp.br
}

RESUMO O presente artigo é um relato de experiência sobre os caminhos percorridos durante o desenvolvimento de uma pesquisa com a metodologia grounded theory construtivista, que investiga os sentidos produzidos por anúncios contraintuitivos com a representação de casais LGBT em famílias brasileiras (homoafetivas e heteroafetivas). 0 objetivo é compartilhar algumas preocupações metodológicas que emergiram e foram deliberadas durante a pesquisa em curso, exigindo autoavaliação e autocorreção do processo investigativo. Dentre essas inquietações, destacam-se os questionamentos realizados pelos agentes parentais negros pesquisados sobre a falta de representatividade de indivíduos negros entre os casais LGBT dos anúncios selecionados para a pesquisa e a oportunidade, percebida a partir desses questionamentos, de aperfeiçoar o referencial teórico com perspectivas que sensibilizassem as lentes interpretativas da investigação para as expressões da interseccionalidade.

PALAVRAS-CHAVE Grounded theory, Consumo, Publicidade, Casais LGBT, Interseccionalidade.

\begin{abstract}
This paper is an experience report on the trajectories taken during the development of a constructivist grounded theory research about effects of counterintuitive ads with same-sex couples on Brazilian heterosexual and LGBT families. This study is guided by a reflexive stance to share some methodological concerns and decision-making that emerged specifically from activities of collective knowledge construction between researchers and research participants (children's parents and/or legal guardians). Among these methodological concerns, the issues raised by Black research participants about the non-representation of Black people within same-sex couples of the selected ads to research practices were most
\end{abstract}


noteworthy. Another opportunity that emerged from this context was the need to strengthen the theoretical framework with perspectives that provide nuance in investigating intersectionality.

KEYWORDS Grounded theory, Consumption, Ads, Same-sex couples, Intersectionality.

RESUMEN El presente artículo es un informe de experiencia sobre los caminos que se están tomando durante el desarrollo de una investigación con la metodología constructivista Grounded Theory, que investiga los significados producidos por anuncios contraintuitivos con la representación de parejas LGBT en las familias brasileñas (homoafectivas y heteroafectivas). Su objetivo es reportar algunas inquietudes metodológicas que surgieron y fueron deliberadas durante la investigación en curso, requiriendo autoevaluación y autocorrección del proceso investigativo. Entre esas inquietudes, se destacan las preguntas planteadas por los agentes parentales negros encuestados sobre la falta de representatividad de los afrodescendientes entre las parejas LGBT de los anuncios seleccionados para la investigación y la oportunidad, percibida con base en esas preguntas, de mejorar el marco teórico con perspectivas que estimulen los lentes interpretativos de la investigación a las expresiones de interseccionalidad.

PALABRAS-CLAVE Grounded theory, Consumo, Publicidad, Parejas LGBT, Interseccionalidad.

\section{INTRODUÇÃO}

O presente artigo é um relato de experiência ${ }^{1}$ (DALTRO; FARIA, 2019; MOCH; GATES, 2000), tensionado por uma análise reflexiva ${ }^{2}$, sobre os caminhos trilhados para o desenvolvimento de uma pesquisa conduzida pelos procedimentos e técnicas da grounded theory construtivista $^{3}$ (CHARMAZ, 2009), no campo das Ciências da Comunicação, especificamente, no horizonte dos estudos que focam os usos e consumos midiáticos nas práticas sociais.

Nessa direção, o objetivo deste trabalho é compartilhar algumas experiências, inquietações e deliberações metodológicas que emergiram, ao longo do processo investigativo, e foram motivadas por questionamentos manifestados durante as atividades de construção conjunta de conhecimento

1. Segundo Mônica Ramos Daltro e Anna Amélia de Faria, o relato de experiência como metodologia "está compreendido como um trabalho de linguagem, uma construção que não objetiva propor a última palavra, mas que tem caráter de síntese provisória, aberta à análise e à permanente produção de saberes novos e transversais. Configura-se como narrativa que, simultaneamente, circunscreve experiência, lugar de fala e seu tempo histórico, tudo isso articulado a um robusto arcabouço teórico, legitimador da experiência enquanto fenômeno científico" (DALTRO; FARIA, 2019, p. 234).

2. Kathy Charmaz orienta que a reflexividade, no contexto da metodologia grounded theory, é uma "análise minuciosa do pesquisador da sua própria experiência de pesquisa, das suas decisões e interpretações de modo a levar o pesquisador para dentro do processo e permitir que o leitor avalie como e até que ponto os interesses, posturas e suposições do pesquisador influenciaram a investigação. Uma postura reflexiva informa como o pesquisador conduz a sua pesquisa, como se relaciona com os participantes da pesquisa e como os representa nos relatórios escritos” (CHARMAZ, 2009, p. 252).

3. Essa expressão foi traduzida para o português como “Teoria Fundamentada”, no entanto, também se observou outras variações menos utilizadas, como "Teoria Fundamentada nos Dados”, “Teoria Embasada”, “Teoria Emergente” ou “Teorização Enraizada”. Neste trabalho, prioriza-se seguir a tendência mundial de utilizar a locução original em inglês, embora em alguns momentos a sua tradução em português possa ser utilizada. 
entre pesquisador (autor deste artigo) e pesquisados (agentes parentais), na etapa de coleta de dados do estudo considerado neste trabalho.

Como se abordará com muita atenção no avançar das discussões deste artigo, essas interpelações foram inscritas pelos pesquisados, informantes da pesquisa, tendo em vista o desconforto deles ao identificar que os materiais de apoio utilizados na pesquisa (os anúncios) não contemplavam adequadamente as representações e expressões identitárias interseccionais. Diante desses questionamentos, com a pesquisa em curso, foram necessárias posturas reflexivas e tomadas de decisões estratégicas para assegurar as boas práticas e a qualidade dos dados ${ }^{4}$ produzidos na investigação, como se buscará descrever e compartilhar nesta oportunidade.

A supracitada investigação tem como título "Experiências de consumo midiático em famílias brasileiras com publicidades contraintuitivas que midiatizam expressões de relações homoafetivas: um estudo em grounded theory" e foi acolhida para ser desenvolvida na Escola de Comunicações e Artes da Universidade de São Paulo (ECA-USP), com apoio da Fundação de Amparo à Pesquisa do Estado de São Paulo (Fapesp).

Essa pesquisa caracteriza-se como um relevante caminho para se construir um quadro teórico explicativo, ou seja, uma teoria substantiva que apoie a compreensão sobre os sentidos que estão sendo produzidos no contexto de famílias brasileiras (heteroafetivas e homoafetivas ${ }^{5}$ ) pelas experiências de interação simbólica com anúncios contraintuitivos ${ }^{6}$, que inscrevem visibilidade e midiatizam representações positivas (relações afetivas) de casais LGBT brasileiros.

4. É relevante destacar que, segundo Anselm Strauss e Juliet Corbin (2008), na metodologia grounded theory, os dados podem ser construídos mediante "entrevistas, notas de observações de campo, vídeos, [...], memorandos, manuais, catálogos e outras formas de materiais escritos e ilustrados. [...] Isolamos os dados e trabalhamos com fotos, palavras, frases, sentenças, parágrafos e outros segmentos de materiais” (STRAUSS; CORBIN, 2008, p. 66). Eugénia M. Fernandes e Ângela Maia (2001) agregam ainda os produtos da cultura da mídia como materiais para suportar a construção da teoria.

5. Os termos "união homoafetiva" e "homoafetividade”, segundo alguns apontamentos da literatura, foram cunhados por Maria Berenice Dias a partir do campo do Direito. A própria autora ratifica essa informação, reforçando que esses registros constam demarcados na obra União homossexual: o preconceito e a justiça [2005]) (DIAS, 2012, p. 40). No entanto, é necessário observar que o termo "homoafetividade" é localizado anteriormente na literatura nacional, no propositivo trabalho Desafios dos Estudos Gays, Lésbicos e Transgêneros, de Denilson Lopes (2004). Na perspectiva de Maria Berenice Dias, de acordo com Maria Regina Castanho França, o termo homoafetivo "vem sendo cada vez mais utilizado, substituindo a palavra homossexual, por se tratar acima de tudo de inclinação afetiva, e não apenas sexual, por outra pessoa do mesmo gênero" (FRANÇA, 2009, p. 31). Em linha consonante, Lopes pontua que pensou "no termo homoafetividade para discutir no mesmo espaço quaisquer relações afetivas entre pessoas do mesmo sexo, desconstruindo a polaridade criada no século passado entre homossexualidade e heterossexualidade e alargando o conceito de homoerotismo, resgatado entre nós por Jurandir Freire Costa” (LOPES, 2004, p. 70-71).

6. A comunicação publicitária contraintuitiva pode ser considerada como uma proposta do campo profissional publicitário que, estrategicamente, faz uso em suas narrativas de "outros/novos" conteúdos acerca de estereótipos dirigidos às minorias sociais, isto é, de “moderadores contraestereótipos” (BLAIR; BANAJI, 1996; BLAIR; LENTON, 2001; DASGUPTA; GREENWALD, 2001), com o objetivo principal de inovar e promover as suas tentativas de apelo para o consumo mercadológico, "violando expectativas intuitivas" (UPAL; 2007; BOYER, 2001) dos receptores acerca dos discursos tradicionalmente veiculados pela mídia. 
Nesse contexto, especialmente, estão sendo considerados os diálogos e as ações que os agentes parentais, indivíduos informantes centrais da investigação, elaboram e direcionam às crianças e aos adolescentes, em idade escolar fundamental, que estejam sob os seus cuidados, frente às narrativas desses anúncios com expressões positivas e humanizadas da afetividade de casais LGBT.

É na busca de alcançar essa compreensão, portanto, que a investigação em referência enfrenta as seguintes questões abertas e gerativas: como as famílias brasileiras estão interagindo com anúncios contraintuitivos que dão visibilidade e midiatizam expressões de relações homoafetivas? Quais sentidos estão sendo construídos ou não pelas experiências de consumo midiático com essas narrativas para o processo de mudança (desenvolvimento) perceptiva e entendimento sobre a homoafetividade na contemporaneidade?

Nesse sentido, de imediato, é pertinente esclarecer que a perspectiva conceitual de consumo utilizada na pesquisa não deve ser confundida, de modo algum, com a restrita ideia de cidadania via consumo de produtos. Mas sim, está inserida numa dimensão mais complexa de expressão de gênese plurissígnica (material e simbólica) que pode, pela sua manifestação, inclusive, promover exercícios de cidadania (GARCÍA CANCLINI, 1995) e de constituição das identidades socioculturais (BAUDRILLARD, 1973; ROCHA, 2010).

Dessa forma, o entendimento de consumo adotado na investigação precisa ser mobilizado para uma compreensão flexível e mais ampla, avançando para ser assimilado para além da aquisição de objetos de consumo e seus procedimentos relacionais. O consumo aqui é considerado também como uma atividade de recepção. Isso porque "a recepção é um tipo de consumo, ainda que psíquico por sua materialidade simbólica” (TRINDADE, 2008, p. 78).

Posto esse cenário, antes de avançar com as discussões agendadas neste artigo, para nivelar o discernimento e possibilitar uma leitura adequada das reflexões centrais que este trabalho aborda, é pertinente elucidar brevemente: o que é (e o que produz) uma grounded theory?

A grounded theory é uma metodologia qualitativa formulada, originalmente, pelos sociólogos estadunidenses Barney Glaser e Anselm Strauss e publicada na clássica obra The Discovery of Grounded Theory, de 1967. Ela é identificada como "um método geral de análise comparativa [...] e um conjunto de procedimentos capazes de gerar [sistematicamente] uma teoria fundada nos dados" (GLASER; STRAUSS, 1967 apud TAROZZI, 2011, p. 17, grifo do autor).

Neste artigo, tendo em vista o seu objetivo estabelecido e os limites deste espaço, não serão apresentadas e discutidas detalhadamente as etapas para a produção de um estudo em grounded theory. Para esses aprofundamentos, sugere-se a leitura do guia prático em Kathy Charmaz (2009, 2014), e para exemplos de aplicação da metodologia em estudos comunicacionais, os trabalhos de Francisco Leite $(2015,2018)$ e Francisco Leite e Leandro Leonardo Batista (2018).

\section{PENSANDO A INTERSECCIONALIDADE NAS TRILHAS E LENTES DA PESQUISA}

Em linha com os procedimentos da grounded theory, para a coleta de dados, ou melhor, para a construção conjunta deles com os agentes parentais informantes da pesquisa, definiu-se como instrumento 
a "entrevista intensiva" (CHARMAZ, 2009, p. 46). Foram realizadas 27 entrevistas, sendo quinze delas com agentes parentais heteroafetivos e doze com homoafetivos. Para suportar e estimular a produção de dados, como já informado, foram exibidos como objetos de exemplificação durante as interlocuções alguns filmes publicitários ${ }^{7}$ contraintuitivos, que apresentam casais LGBT e midiatizam positivamente expressões acerca da homoafetividade.

Esses anúncios selecionados foram veiculados na TV e internet ${ }^{8}$, bem como identificados mediante um levantamento exploratório, não exaustivo, de trabalhos científicos que apresentavam essas materialidades midiáticas como objeto de suas análises de conteúdo, análises de discurso, análises semióticas, entre outras. Esse levantamento inicialmente aconteceu no final do primeiro semestre de 2019.

As fontes pesquisadas foram os anais de relevantes eventos científicos brasileiros do campo da comunicação, considerando o período de 2000 a 2020, como os encontros anuais da Associação Nacional dos Programas de Pós-Graduação em Comunicação (Compós), o Congresso Brasileiro de Ciências da Comunicação (Intercom) e Encontro Nacional de Pesquisadores em Publicidade e Propaganda (Pró-Pesq PP). Também foram considerados trabalhos científicos identificados pelo Google Acadêmico, nas cinco primeiras páginas do resultado de buscas realizadas com as combinações da string: publicidade; propaganda; anúncios; homossexualidade; homoafetividade; lésbica; gay; bissexual; travesti; transexual; e LGBT.

Todos os trabalhos identificados foram lidos e os anúncios extraídos, caso atendessem aos seguintes critérios: 1) que fosse anúncio audiovisual; 2) que a narrativa ofertasse visibilidade qualitativa (estímulo contraintuitivo) às expressões de relações homoafetivas dentro do seu apelo principal para o consumo de produtos; 3) que a narrativa não fosse propaganda governamental de saúde pública para a promoção e conscientização de prevenção ao HIV ou Infecções Sexualmente Transmissíveis (IST), tendo em vista os elementos distratores e estigmas sociais que tal narrativa pudesse também carregar; e, por fim, 4) que os anunciantes e marcas estejam ainda atuantes no mercado brasileiro.

Dessa forma, foram selecionados como material de suporte para dinamizar as conversas das entrevistas os anúncios que tiveram os seus conteúdos e discursos analisados nas investigações indicadas no Quadro 1. Os anúncios considerados foram veiculados entre os anos 2000 e 2018.

Nesse proceder, ainda levando em consideração os quatro critérios de seleção apontados, os anúncios identificados nas análises realizadas por Baggio (2009, 2013) e Leal (2013) não foram considerados, tendo

7. Segundo Tarozzi, esses materiais "podem representar estímulos úteis para conduzir entrevistas em que, a partir [deles] [...], pede-se aos participantes comentar o significado” (TAROZZI, 2011, p. 120) presente nos mesmos para assim apoiar a construção do estudo substantivo em elaboração.

8. É relevante esclarecer que não se busca na pesquisa explorar as mediações institucionais dos meios de comunicação (televisão $\mathrm{x}$ internet), mas sim considerar o potencial de suas narrativas, tendo em vista as expressões contraintuitivas associadas às relações homoafetivas. O recorte por anúncios audiovisuais veiculados na TV e internet deve-se, simplesmente, ao fato de esses serem os meios de comunicação mais acessados no Brasil, segundo a Pesquisa Brasileira de Mídia 2016: a TV é o meio de comunicação mais acessado pelos brasileiros, sendo mencionada pela quase totalidade da amostra (89\%), sendo seguida pela internet (49\%). Disponível em: https://bitlybr.com/8XnWaCte. Acesso em: 10 ago. 2020. 
em vista que os autores consideraram, para esses estudos, anúncios impressos. Dos anúncios analisados por Iribure (2008), três também foram desconsiderados, a saber: AIDS "Namorados” (2002); Prevenção AIDS HSH (2008), ambos por serem propagandas governamentais de prevenção ao HIV; e o anúncio “Qual o seu jeito de beijar?” (2000), do provedor de internet O Site, marca descontinuada no Brasil.

Cabe enfatizar, antes de prosseguir, que os anúncios analisados nesses trabalhos foram extraídos, como dito, da mídia audiovisual televisiva e da internet e não estavam necessariamente sendo veiculados nos “fluxos midiáticos" (PIEDRAS, 2007) no período em que as entrevistas foram realizadas.

Dessarte, tais narrativas foram selecionadas especialmente para se compreender os sentidos que podem ou não ser produzidos quando da interação de agentes parentais com elas.

Quadro 1. Primeira fase - Anúncios contraintuitivos com casais LGBT.

\begin{tabular}{|c|c|c|c|c|c|c|}
\hline ANUNCIANTE & PRODUTO & ANÚNCIO & ANO & ANÁLISE EM & MEIO & $\begin{array}{l}\text { EX. RELAÇÕES } \\
\text { HOMOAFETIVAS }\end{array}$ \\
\hline \multicolumn{7}{|c|}{ Primeira busca de anúncios - trabalhos científicos } \\
\hline 1. Fiat do Brasil & Carro Palio & Escola ${ }^{9}$ & 2000 & $\begin{array}{l}\text { LEITE (2007); } \\
\text { IRIBURE (2008). }\end{array}$ & TV & $\begin{array}{l}\text { Casal Lésbico } \\
\text { (branco) }\end{array}$ \\
\hline 2. Chevrolet & $\begin{array}{l}\text { Novo Carro } \\
\text { Vectra GT }\end{array}$ & Saia da linha ${ }^{10}$ & 2007 & IRIBURE (2008). & TV & $\begin{array}{l}\text { Casal Lésbico } \\
\text { (branco) }\end{array}$ \\
\hline $\begin{array}{l}\text { 3. Nycomed } \\
\text { Pharma }\end{array}$ & $\begin{array}{l}\text { Pomada } \\
\text { Nebacetin }\end{array}$ & Famílias ${ }^{11}$ & 2008 & $\begin{array}{c}\text { IRIBURE; CARVALHO } \\
\text { (2015); SPADIN } \\
\text { (2015); CHIARELLI } \\
\text { JR; MACEDO (2016). }\end{array}$ & TV & $\begin{array}{c}\text { Casal gay e filho } \\
\text { (brancos) }\end{array}$ \\
\hline 4. Natura & Institucional & Relações ${ }^{12}$ & 2013 & $\begin{array}{c}\text { MULATINHO; } \\
\text { BEZERRA (2016). }\end{array}$ & TV & $\begin{array}{c}\text { Casal gay } \\
\text { (branco) } \\
\text { Casal lésbico } \\
\text { (branco) }\end{array}$ \\
\hline 5. O Boticário & $\begin{array}{l}\text { Perfume } \\
\text { Egeo }\end{array}$ & $\begin{array}{l}\text { Um Dia dos } \\
\text { Namorados } \\
\text { para todas } \\
\text { as formas de } \\
\text { amor }^{13}\end{array}$ & 2015 & $\begin{array}{l}\text { SILVA; LAHNI (2015); } \\
\text { REINO; CARVALHO } \\
\text { (2015); OLIVEIRA } \\
\text { (2015, 2016); } \\
\text { CHIARELLI; MACEDO } \\
\text { (2016); LEAL (2016); } \\
\text { SILVA (2016); CRUZ; } \\
\text { VILLEGAS (2016); } \\
\text { IRIBURE (2016); } \\
\text { MOZDZENSKI; SILVA } \\
\text { (2016); } \\
\text { SANTOS; MARMITT } \\
\text { (2017); MENDES } \\
\text { (2017). }\end{array}$ & TV & $\begin{array}{l}\text { Casal gay } \\
\text { (branco) } \\
\text { Casal lésbico } \\
\text { (branco) }\end{array}$ \\
\hline $\begin{array}{l}\text { 6. Gol Linhas } \\
\text { Aéreas }\end{array}$ & Institucional & $\begin{array}{c}\text { Dias das mães } \\
\text { - Gilberto e } \\
\text { Rodrigo }^{14}\end{array}$ & 2015 & $\begin{array}{c}\text { SPADIN (2015); } \\
\text { CHIARELLI JR.; } \\
\text { MACEDO (2016); } \\
\text { MOZDZENSKI; SILVA } \\
\text { (2016). }\end{array}$ & Internet & $\begin{array}{c}\text { Casal gay } \\
\text { (branco) } \\
\text { e filho (negro/ } \\
\text { preto) }\end{array}$ \\
\hline
\end{tabular}

(continua)

9. Disponível em: https://www.youtube.com/watch?v=3FKGYSe-XW8. Acesso em: 10 ago. 2020.

10. Disponível em: https://www.youtube.com/watch?v=qshGRuDfbFQ. Acesso em 10 ago. 2020.

11. Disponível em: https://www.youtube.com/watch?v=5anyL_SdFic. Acesso em: 10 ago. 2020.

12. Disponível em: https://www.youtube.com/watch?v=79A8EDXf9hA. Acesso em: 10 ago. 2020.

13. Disponível em: https://www.youtube.com/watch?v=p4b8BMnolDI. Acesso em: 10 ago. 2020.

14. Disponível em: https://www.youtube.com/watch?v=Co6Oe-9PRqY. Acesso em: 10 ago. 2020. 
Quadro 1. Continuação.

\begin{tabular}{|c|c|c|c|c|c|c|}
\hline ANUNCIANTE & PRODUTO & ANÚNCIO & ANO & ANÁLISE EM & MEIO & $\begin{array}{c}\text { EX. RELAÇÕES } \\
\text { HOMOAFETIVAS }\end{array}$ \\
\hline \multicolumn{7}{|c|}{ Primeira busca de anúncios - trabalhos científicos } \\
\hline 7. Mondelez & $\begin{array}{l}\text { Sonho de } \\
\text { Valsa }\end{array}$ & $\begin{array}{l}\text { Pense Menos, } \\
\text { Ame Mais! } \\
\text { "Casais } \\
\text { Apaixonados"15 }\end{array}$ & 2015 & $\begin{array}{c}\text { OLIVEIRA (2015, } \\
\text { 2016); RUAN; } \\
\text { KNOBBE (2016); } \\
\text { SANTOS; MARMITT } \\
\text { (2017). } \\
\end{array}$ & Internet & $\begin{array}{l}\text { Casal lésbico } \\
\text { (branco) }\end{array}$ \\
\hline 8. Coca-Cola & Institucional & $\mathrm{SMS}^{16}$ & 2015 & $\begin{array}{c}\text { CRUZ; VILLEGAS } \\
\text { (2016). }\end{array}$ & Internet & $\begin{array}{l}\text { Casal gay } \\
\text { (branco) }\end{array}$ \\
\hline 9. Houaiss & $\begin{array}{c}\text { Dicionário } \\
\text { Houaiss }\end{array}$ & \#Todasasfamílias & 2016 & $\begin{array}{l}\text { CRUZ; VILLEGAS } \\
\text { (2016). }\end{array}$ & Internet & $\begin{array}{c}2 \text { Casais Gay } \\
\text { (brancos) } \\
2 \text { Casais lésbicos } \\
\text { (brancos) }\end{array}$ \\
\hline 10. Loja Gang & Loja Gang & Gang Instalove ${ }^{18}$ & 2016 & IRIBURE (2018). & TV & $\begin{array}{l}\text { Casal gay } \\
\text { (branco) }\end{array}$ \\
\hline $\begin{array}{l}\text { 11. Westwing } \\
\text { Casa \& } \\
\text { Decoração }\end{array}$ & |Institucional & $\begin{array}{c}\text { Dia dos } \\
\text { Namorados: o } \\
\text { que é Amor }{ }^{19}\end{array}$ & 2016 & $\begin{array}{l}\text { MOZDZENSKI; SILVA } \\
\text { (2016). }\end{array}$ & Internet & $\begin{array}{c}\text { Casal lésbico } \\
\text { (negro/pardo) } \\
\text { Casal gay } \\
\text { (branco) } \\
\text { Casal } \\
\text { heterossexual: } \\
\text { mulher transexual } \\
\text { e homem } \\
\text { heterossexual } \\
\text { (brancos) }\end{array}$ \\
\hline 12. Airbnb & $\begin{array}{l}\text { Airbnb } \\
\text { Citizen }\end{array}$ & $\begin{array}{c}\text { Abra sua } \\
\text { porta para a } \\
\text { diversidade }\end{array}$ & 2018 & $\begin{array}{l}\text { SILV; HANSEN } \\
\text { (2020). }\end{array}$ & Internet & $\begin{array}{l}\text { Casal lésbico } \\
\text { (branco) }\end{array}$ \\
\hline
\end{tabular}

Fonte: Elaborado pela autora (2020).

Portanto, considerando essa lógica, o conceito de "ponto de contato" (DI NALLO, 1999; TRINDADE, 2008) se apresenta pertinente para entender o contexto de consumo midiático produzido quando da realização das entrevistas, visto que o entendimento desse termo sugere uma situação específica de interação com narrativas midiáticas.

Por conseguinte, no decorrer das entrevistas foi identificado um questionamento recorrente, partindo, especialmente, de alguns agentes parentais negros que colaboraram com a pesquisa, tanto do grupo heteroafetivo quanto do grupo homoafetivo. Esses agentes parentais, após a interação com os anúncios, generosamente, observavam que o conjunto dos filmes publicitários contraintuitivos selecionado e apresentado a eles $^{21}$ não incluía a representação de casais LGBT negros. Por exemplo, algumas dessas vozes expressaram:

15. Disponível em: https://www.youtube.com/watch?v=HYWyzYJhQyk. Acesso em: 10 ago. 2020.

16. Disponível em: https://www.youtube.com/watch?v=Ih75j5BoL10. Acesso em: 10 ago. 2020.

17. Disponível em: https://www.youtube.com/watch?v=Bq1gEOlRD40. Acesso em: 10 ago. 2020.

18. Disponível em: https://www.youtube.com/watch?v=aw4asgpfx2Y. Acesso em: 10 ago. 2020.

19. Disponível em: https://www.youtube.com/watch?v=Q5vqXj43Jzw. Acesso em: 10 ago. 2020.

20. Disponível em: https://www.youtube.com/watch?v=MysuZ9INQKU. Acesso em: 10 ago. 2020.

21. É pertinente apontar que, durante as entrevistas, o conjunto de anúncios era disponibilizado para os entrevistados assistirem em um tablet. Os agentes parentais podiam assistir livremente os anúncios de interesse e quantas vezes desejassem. A proposta dessas leituras visava alcançar, pelo olhar dos agentes parentais, os potenciais efeitos de sentidos e repercussões que tais narrativas contraintuitivas pudessem produzir e tensionar no cotidiano de famílias brasileiras, como já indicado. 
Faltam negros nos comerciais. Existem negros gays [na sociedade]. Existem casais inter-raciais, que é uma coisa que as pessoas têm um tabu. [...]. Então, acho que faltaram aí algumas inserções de negros e casais inter-raciais. A naturalidade. Faltou o beijo. Não precisa ser um beijo sexualizado, mas faltou um afeto, que é o que faz as pessoas ficarem normais e assimilarem isso como comum. (LJRFV, homoafetivo, pai, negro)

Eu acho que na verdade o que falta é a representatividade do negro na televisão. [...]. Então, como [os anúncios] estão falando de formas de amar, poderiam ter passado e colocado uns casais negros, algo assim. Mas, de resto eu achei tudo maravilhoso. Eu senti falta. [...]. Poderia ter mostrado um casal de negro. Isso ajudaria. (SACS, heteroafetivo, mãe, negra)

Ao praticar uma escuta atenta e ativa, direcionada a essas observações, foi possível perceber que havia nelas, explícita e implicitamente, indicações oportunas para a realização de autoavaliação e aperfeiçoamento dos procedimentos e enunciados da pesquisa. Especialmente no que tange a indicação sobre a não representatividade de indivíduos negros nas narrativas dos anúncios utilizados nas entrevistas. Nesse ponto, é preciso notar que essa indicação dos agentes parentais é bem complexa e exige muito cuidado na sua abordagem, pois ela inscreve no contexto da pesquisa o critério "subjetivo" da leitura de raça/cor dos indivíduos LGBT representados nos filmes publicitários.

Com transparência e respeito aos informantes da pesquisa, sem o propósito de contestar as suas vozes, mas valorizando-as incisivamente para o aperfeiçoamento da investigação, é preciso indicar que se pensava existir entre os anúncios selecionados um com a representação de um casal lésbico de mulheres negras (Westwing Casa \& Decoração). No entanto, pelo que se observou, o casal não foi identificado/lido como negro pela maioria dos agentes parentais negros entrevistados, por exemplo.

Esses olhares, inclusive, são dissonantes em relação aos de Mozdzenski e Silva (2016), que originalmente analisaram o referido anúncio e identificaram o referido casal como sendo formado por duas mulheres negras. Todavia, essa dissonância confirma que o critério raça/cor dá margem a diferentes interpretações, especialmente no que tange perceber e classificar indivíduos identificados como pardos. Mas, como se sabe (GUIMARÃES, 2011; PIZA; ROSEMBERG, 1999), essa discussão não é novidade no contexto político e social brasileiro.

Na configuração desse enquadramento, é imperativo destacar a relevância dos postulados da metodologia grounded theory sobre a construção coletiva dos conhecimentos e direcionamentos do trabalho investigativo mediante a produção de sentidos entre pesquisador e pesquisados. Esse caminho assegurou o estabelecimento de diálogos acolhedores nos quais os agentes parentais sentiam-se à vontade para compartilhar confortavelmente as suas visões de mundo, assim, fornecendo dados relevantes ${ }^{22}$ para a pesquisa.

Com efeito, é pertinente informar que desde o protocolo da investigação, o pesquisador, autor deste artigo, se preocupou em agregar ao conteúdo da pesquisa as experiências, as opiniões, os sentimentos e

22. Esses dados relevantes devem fornecer à pesquisa em grounded theory "material sólido para construção de uma análise significativa. Os dados relevantes são detalhados, focados e completos. Eles revelam as opiniões, os sentimentos, as intenções e as ações dos participantes, bem como o contexto e a estrutura de suas vidas” (CHARMAZ, 2009, p. 30). 
as intenções de diversificados perfis de agentes parentais (homoafetivos, heteroafetivos, negros e não negros, mulheres, homens, classes econômicas etc.), tentando garantir para a grounded theory edificada perspectivas múltiplas e, provavelmente, implicadas pelas marcas identitárias interseccionais dos informantes-chave.

Dessa forma, ao mesmo tempo em que esse cuidado, de um lado, assegurou sensibilidades e olhares diversos para o estudo, como a crítica feita aos anúncios pelos agentes parentais negros, de outro lado, por exemplo, o pensamento sobre a escolha dos participantes focou a diversidade de perfis. Porém, essa diversidade estava, inicialmente, de modo involuntário, estruturada por um "pensamento binário", conforme postula Patricia Hill Collins.

De acordo com Collins, esse raciocínio seria uma "forma de conceituação das realidades que divide os conceitos em duas categorias mutuamente excludentes, por exemplo, branco/preto, homem/mulher, razão/emoção e heterossexualidade/homossexualidade" (COLLINS, 2019, p. 461). Ou seja, é um proceder que implica e define as diferenças por contraste. Contudo, essas estruturas de diferenças edificadas por oposição suportam opressões interseccionais, resultantes de "relações de superioridade e inferioridade, vínculos hierárquicos que se misturam a economias políticas de opressão de raça, gênero e classe” (COLLINS, 2019, p. 139).

Com o atravessamento dessa orientação de Collins, é possível pensar que o olhar do pesquisador tenha se estruturado nesse foco de garantir para os dados da pesquisa os sentidos da diversidade, porém sem considerar e tensionar adequadamente a questão interseccional nas expressões e construções do conjunto da pesquisa.

Por essa razão, a indicação dos agentes parentais sobre a inadequada representação de indivíduos negros entre os casais LGBT dos anúncios foi uma contribuição muito significativa para a pesquisa, pois possibilitou observar (e reparar) com mais nitidez que a expressividade dessas representações interseccionais e as suas implicações estavam escapando do crivo analítico da pesquisa.

Na mesma linha, esse olhar dos informantes também estimulou aperfeiçoamentos no processo da pesquisa, como os esforços prioritários para identificar "novos/outros" anúncios contraintuitivos brasileiros com a representação explícita de casais LGBT negros. Paralelamente, o pensamento sobre a crítica queer of color (FERGUSON, 2004), que amplia e tensiona o conceito de interseccionalidade (CRENSHAW, 1989), foi integrado no referencial teórico da investigação, como se aborda no próximo tópico que inicialmente contemplava apenas os estudos da midiatização na perspectiva socioconstrutivista.

No entanto, antes de avançar, é pertinente questionar: como foi conduzir e aplicar adequadamente essa autoavaliação e aperfeiçoamentos em uma pesquisa grounded theory em curso, sem invalidar ou fragilizar os dados já produzidos?

$\mathrm{Na}$ direção de responder essa indagação, resgatam-se algumas orientações de Kathy Charmaz sobre as características de investigações qualitativas. Segundo essa autora, nesse tipo de investigação, mesmo em desenvolvimento,

Podemos acrescentar novas peças ao quebra-cabeça da pesquisa ou criamos quebra-cabeças inteiramente novos - enquanto coletamos os dados -, e isso pode ocorrer até mesmo posteriormente, durante a análise. A flexibilidade da pesquisa qualitativa permite ao pesquisador seguir as indicações que vão surgindo. (CHARMAZ, 2009, p. 31, grifo da autora) 
No mesmo espírito, porém de modo específico, Massimiliano Tarozzi pontua que as investigações desenvolvidas com a metodologia grounded theory podem se autoavaliar e têm capacidade inerente para autocorreção. Dessa maneira, a "característica da modificabilidade assegura o fato que, se emergirem em outros lugares ou tempos elementos novos que não confirmem características assim como foram anunciadas [...], a [grounded theory] não é falsificada” (TAROZZI, 2011, p. 164). Os dados produzidos também não são descartados. Eles são refinados, se oportuno, e agregados aos novos dados, seguindo a estratégia de comparação constante da metodologia.

Frente à segurança dessas orientações, no próximo tópico são compartilhadas as iniciativas deliberadas para ajustar e aprimorar o percurso de construção da pesquisa em tela. Desse modo, inicia-se abordando a busca pelo fortalecimento das lentes críticas da investigação com o agregar do aporte teórico da crítica queer of color.

\section{INTERSECCIONALIDADE E A CRÍTICA QUEER OF COLOR}

O conceito de interseccionalidade, acolhido neste artigo, bem como na pesquisa grounded theory, foi cunhado por Kimberle Crenshaw, em 1989, nos Estados Unidos. Esse termo ilustra e reverbera toda uma tradição de saberes advindo do pensamento feminista negro estadunidense, conforme pontua Collins (2017). A abordagem de Crenshaw sobre a interseccionalidade considera três aspectos: estrutural, político e representacional. Para ela,

a interseccionalidade é uma conceituação do problema que busca capturar as consequências estruturais e dinâmicas da interação entre dois ou mais eixos da subordinação. Ela trata especificamente da forma pela qual o racismo, o patriarcalismo, a opressão de classe e outros sistemas discriminatórios criam desigualdades básicas que estruturam as posições relativas de mulheres, raças, etnias, classes e outras. Além disso, a interseccionalidade trata da forma como ações e políticas específicas geram opressões que fluem ao longo de tais eixos, constituindo aspectos dinâmicos ou ativos do desempoderamento. (CRENSHAW, 2002, p. 177)

Em linha com esse entendimento, Joshua C. Collins e Caitlin Taborda-Whitt ressaltam, porém, que a interseccionalidade, como visto na literatura, tradicionalmente tem as suas bases em pesquisas mais direcionadas particularmente para mulheres negras. Desse modo, "menos investigadas são as experiências e perspectivas daqueles que se identificam como queer (lésbica, gay, bissexual ou transgênero) ${ }^{23}$ e como uma minoria racial e/ou étnica - as pessoas queer of color [...]”. (COLLINS; TABORDA-WHITT, 2017, p. 1, grifo dos autores, tradução livre).

Nesse propósito, grosso modo, a crítica queer of color é também uma abordagem teórica responsiva ao uso da retórica da teoria queer

23. 'Reconhecemos que definir 'queer' como lésbica, gay, bissexual ou transgênero (LGBT) pode ser considerado limitante por normas mais contemporâneas que abrangem identidades como gênero, pansexual, bipolar e inconformista de gênero, para citar alguns” (COLLINS; TABORDA-WHITT, 2017, p. 1, tradução livre). 
clássica que, segundo Johnson (2015, p. 231, tradução livre), “considera as identificações fictícias’ e, em última análise, privilegia a branquitude”.

Desse modo, em linha com as propostas do pensamento interseccional, porém o ampliando, a crítica ou análise queer of color ${ }^{24}$ é outro aporte teórico acionado para fortalecer as lentes analíticas da pesquisa grounded theory, em foco neste artigo. Esse termo foi cunhado por Roderick Ferguson (2004) para nomear um conjunto de obras que despontaram no início do século 21, advindas de campos tradicionais do saber, como a antropologia, a sociologia e a literatura inglesa, e de trabalhos interdisciplinares, como os estudos feministas, estudos culturais e estudos raciais/étnicos. Para Ferguson, a crítica queer of color

[...] interroga as formações sociais como as intersecções de raça, gênero, sexualidade e classe, com particular interesse em como essas formações correspondem aos e divergem dos ideais e práticas nacionalistas. A análise queer of color é um empreendimento heterogêneo composto do feminismo negro, análise materialista, teoria pós-estruturalista e crítica queer. (FERGUSON, 2004, p. 149, tradução livre)

A crítica queer of color tem, de acordo com Martin F. Manalansan IV (2018), o seu horizonte analítico fundamentado pelos saberes da teoria feminista, especialmente nos trabalhos de Gloria Anzaldúa (1990) e Audrey Lorde (1994), entre outros; nos estudos queer e nos estudos de crítica racial/étnica de Chandan Reddy (2011) e Siobhan B. Somerville (2000); e estudos da diáspora/migração, de Gayatri Gopinath (2005). Os estudos indígenas, como os de Linda Tuhiwai Smith (1999), também devem ser considerados, como lembra Edward Brockenbrough (2015). Nessa articulação de saberes, "Ferguson amplia a noção de interseccionalidade de Kimberley Crenshaw (1989) [...] dentro de quadros pós-nacionalistas e transnacionalistas e a fundamenta nas experiências e histórias de indivíduos queer não brancos” (MANALANSAN IV, 2018, p. 1).

Em síntese, a orientação da crítica queer of color interroga criticamente as formações sociais, as matrizes interseccionais de raça, gênero, sexualidade, classe e nacionalidade a partir de dentro de suas estruturas, com o propósito de evidenciar e, desse modo, "transformar os fundamentos normativos dessas formações [...]” (ADJEPONG, 2019, p. 8).

Essas noções teóricas sobre as perspectivas integradas ao quadro teórico da pesquisa grounded theory em tela têm o intuito de provocar mais nitidez nas lentes analíticas da pesquisa para as expressões da interseccionalidade. Compartilha-se a seguir os esforços que também foram investidos para identificar anúncios brasileiros com a representação de casais LGBT negros ou inter-raciais para integrá-los ao conjunto de filmes publicitários utilizados nas entrevistas da pesquisa considerada neste artigo.

\section{"OUTROS/ NOVOS” ANÚNCIOS. "OUTROS/ NOVOS" DADOS RELEVANTES?}

Primeiramente, tinha-se consciência que não seria fácil encontrar equivalência nas materialidades publicitárias produzidas no contexto

24. Ferguson (2004), de modo alternado, ao longo das suas discussões, utiliza os termos sinônimos crítica e análise. 
midiático brasileiro, pois mesmo sendo $55 \%$ da população, de acordo com o IBGE, os indivíduos negros (pretos e pardos) ainda são subrepresentados na publicidade no Brasil. Os resultados recentes da pesquisa TODOX, da agência de publicidade Heads, publicados em 2019, apontam, por exemplo, que a representação em anúncios televisivos de protagonistas negras é de 25\%; já para homens, essa participação nas peças publicitárias é de 13\% (INFANTE, 2019).

Já o levantamento feito pelo Grupo de Estudos de Ação Afirmativa (Gemaa), da Universidade Estadual do Rio de Janeiro (UERJ), demonstra que indivíduos pretos e pardos (negros) representam só 16\% das figuras humanas em publicidade [impressa] no Brasil (BOLDRINI, 2020). Especificamente considerando a publicidade nas redes sociais, o estudo da Elife e agência SA365, por meio da plataforma de gestão de mídias sociais Buzzmonitor, indica que "os brancos estão presentes em $87 \%$ das publicações de marcas [...], contra 34\% de negros [...]” (NEGROS ainda são..., 2020).

Mas, afinal, qual seria a representação de indivíduos LGBT nos anúncios brasileiros? E os indivíduos LGBT negros, quanto representam nesse recorte? No que tange à representatividade LGBT, segundo outra pesquisa TODOX, divulgada anteriormente em 2018, entre a publicidade televisiva, “ela representa 0,33\%" (ABDO, 2018). Já analisando os anúncios em redes sociais, a pesquisa da Elife e agência SA365 mostra que a representação LGBT está presente "em somente $4 \%$ das publicações, sendo identificadas a partir de figuras públicas e demonstrações afetivas” (NEGROS ainda são..., 2020).

Especificamente sobre a intersecção da representatividade de pessoas LGBT negras nos anúncios, não foram encontrados dados relativos nesses levantamentos, bem como também não foram localizadas referências em outras fontes similares divulgadas em anos anteriores. A não divulgação desses dados interseccionais é um ponto a ser considerado com muita atenção e crítica em estudos futuros. Essa desconsideração acaba por apagar a possibilidade de compreensão dos significados que esses dados podem reportar e promover socialmente. Mas, como se aprendeu com Eni Orlandi (1995), o silêncio e suas formas também significam.

Desse modo, diante da ausência de dados é que se observam novamente as camadas interseccionais que atravessam esses enquadramentos de interpretação social. É latente a percepção, frente aos dados dessas pesquisas, que entre as frágeis aberturas de representatividade na publicidade aos indivíduos LGBT na contemporaneidade, os obstáculos da exclusão novamente são inscritos aos indivíduos negros desse grupo (LEITE; BATISTA, 2019).

Por conseguinte, esses dados confirmam, portanto, que o padrão da imagem de LGBT na publicidade brasileira é inscrito aos indivíduos brancos, não negros. Frente a esse cenário, fica latente a perpetuação de uma "hierarquia da diferença dentro da diferença" (ALEXANDER, 2018, p. 502, tradução livre) operando em uma "matriz de dominação", como bem aponta Patricia Hill Collins (2019, p. 57). Logo, essa é uma agenda a ser enfrentada com mais atenção. É preciso tensionar e pensar sobre a diversidade da diversidade! ${ }^{25}$

25. Utiliza-se neste trabalho os conceitos de diferença e diversidade de modo articulado, porém, eles carregam sentidos distintos, conforme uma leitura introdutória organizada por Richard Miskolci (2017). 
Todavia, é no encontro com os trabalhos de André Iribure (2018) que outros dados são identificados e inseridos nessa discussão, deixando ainda mais lúcidas as razões do não encontro mais expressivo de filmes publicitários com a representação de indivíduos LGBT negros. No tocante a essas questões, por exemplo, Iribure situa que a primeira veiculação de um indivíduo LGBT negro, em um anúncio televisivo no Brasil, só teria ocorrido recentemente, em 2017, em uma campanha da marca de cosmético Avon. O anúncio foi estrelado por uma mulher negra (parda) e trans, a cantora e apresentadora de TV $\mathrm{Mel}^{26}$. Essa indicação de Iribure, no recorte de anúncios televisivos, faz muito sentido frente às leituras dos levantamentos apresentados a priori.

Cabe ressaltar que essa assertiva de André Iribure tem como base o importante levantamento que ele vem realizando, desde 2008, sobre as representações LGBT na publicidade de TV aberta do país. Somam-se já nesse esforço de recolha e análise mais de 120 anúncios. Entre esses filmes publicitários, o mais antigo é de 1979, indicado por Iribure como o provável primeiro anúncio televisivo do país com representação LGBT (2008, p. 148). A peça apresenta um homem branco e gay performando um mordomo para promover o produto Creme de Leite Paulista "Fresco".

Diante desse contexto de violência simbólica ${ }^{27}$, latente especialmente no espaço publicitário tradicional, esforços foram redirecionados para as mídias sociais na internet na tentativa de localizar anúncios que abordassem a representação de indivíduos negros em casais LGBT e que pudessem somar às expectativas da pesquisa em grounded theory em tela. Esse focalizar nas redes sociais considerou os resultados da pesquisa da Elife e agência SA365, que indica ser de 4\% a representação de personagens LGBT nesses espaços.

Nessa direção, é importante informar que os primeiros anúncios levantados no início da pesquisa foram enquadrados como anúncios da "primeira fase das entrevistas". Já os novos anúncios foram identificados como "segunda fase das entrevistas" e integrados ao conjunto dos primeiros.

Posto essa ordem, informa-se que não foram identificados anúncios com a representação de casais LGBT negros em trabalhos científicos, como metodologicamente se identificou na primeira fase. Desse modo, adotou-se uma nova estratégia de buscar tais anúncios em conteúdos jornalísticos, aplicando uma busca exploratória no Google, com os mesmos termos buscados na primeira fase, agregando as palavras: negro/negra, preto/preta e pardo/parda. É pertinente informar que, entre os novos anúncios identificados, apenas um não foi extraído de materiais jornalísticos, mas foi fortemente indicado por um dos agentes parentais.

26. Disponível em: https://bitlybr.com/2UtlEP9. Acesso em: 10 ago. 2020.

27. Segundo Pierre Bourdieu, a violência simbólica pode ser entendida com "violência suave, insensível, invisível as suas próprias vítimas, que se exerce essencialmente pelas vias puramente simbólicas da comunicação e do conhecimento, ou, mais precisamente, do desconhecimento, do reconhecimento, ou, em última instância, do sentimento" (BOURDIEU, 1999, p. 7-8). Em outra oportunidade, de acordo com a tradução de José Vicente Tavares do Santos, Bourdieu reforça que a violência simbólica ou dominação simbólica são “[...] formas de coerção que se baseiam em acordos não conscientes entre as estruturas objetivas e as estruturas mentais” (Bourdieu, 2012 apud SANTOS, 2015, p. 184). 
Quadro 2. Segunda fase - Anúncios contraintuitivos com casais LGBT.

\begin{tabular}{|c|c|c|c|c|c|c|}
\hline ANUNCIANTE & PRODUTO & ANÚNCIO & ANO & ANÁLISE EM & MEIO & $\begin{array}{l}\text { EX. RELAÇÕES } \\
\text { HOMOAFETIVAS }\end{array}$ \\
\hline \multicolumn{7}{|c|}{ Segunda Busca de Anúncios - Matérias Jornalísticas } \\
\hline 13. Natura & $\begin{array}{c}\text { Natura } \\
\text { Presentes }\end{array}$ & $\begin{array}{l}\text { Todas as } \\
\text { Mães }^{28}\end{array}$ & 2014 & EXAME $(2014)^{29}$ & TV & $\begin{array}{l}\text { Casal lésbico e } 2 \text { filhos } \\
\text { (brancos) }\end{array}$ \\
\hline 14. Netflix & Institucional & $\begin{array}{l}\text { Veja além da } \\
\text { ficção }{ }^{30}\end{array}$ & 2016 & $\begin{array}{l}\text { MEIO E } \\
\text { MENSAGEM } \\
(2016)^{31}\end{array}$ & Internet & $\begin{array}{c}\text { Casal lésbico inter-racial } \\
\text { (branca e preta) } \\
\text { Casal gay (branco) }\end{array}$ \\
\hline 15. Vick & $\begin{array}{c}\text { Vick } \\
\text { Vaporub }\end{array}$ & $\begin{array}{l}\text { O poder do } \\
\text { toque é para } \\
\text { todos }^{32}\end{array}$ & 2017 & $\begin{array}{c}\text { GRANDES } \\
\text { NOMES DA } \\
\text { PROPAGANDA } \\
(2017)^{33}\end{array}$ & Internet & $\begin{array}{l}2 \text { casais gays (brancos) } \\
\text { Casal lésbico (branco) } \\
\text { Casal lésbico inter-racial } \\
\text { (branca e negra/ parda) }\end{array}$ \\
\hline $\begin{array}{l}\text { 16. Mercado } \\
\text { Livre }\end{array}$ & $\begin{array}{l}\text { Mercado } \\
\text { Livre }\end{array}$ & $\begin{array}{c}\text { Sobre Mães - } \\
\text { Sophia }^{34}\end{array}$ & 2018 & EXAME $(2018)^{35}$ & Internet & $\begin{array}{c}\text { Casal lésbico inter-racial } \\
\text { (branca e negra/ parda) } \\
\text { e filha (branca) }\end{array}$ \\
\hline 17. Bradesco & Institucional & $\begin{array}{l}\text { Dia de todos } \\
\text { os pais }\end{array}$ & 2018 & $\begin{array}{l}\text { Indicado por } \\
\text { agente parental } \\
\text { homoafetivo } \\
\text { negro }\end{array}$ & Internet & $\begin{array}{c}\text { Casal gay inter-racial } \\
\text { (branco e negro/ preto) e } \\
2 \text { filhos (branco e negra/ } \\
\text { parda) }\end{array}$ \\
\hline $\begin{array}{l}\text { 18. Natura } \\
\text { Faces }\end{array}$ & $\begin{array}{c}\text { Coleção } \\
\text { do Amor - } \\
\text { Maquiagens }\end{array}$ & $\begin{array}{l}\text { Coleção do } \\
\text { Amor }^{37}\end{array}$ & 2019 & $\begin{array}{c}\text { CLUBE DE } \\
\text { CRIAÇÃO SP } \text { SP }^{38}\end{array}$ & Internet & $\begin{array}{c}\text { Casal lésbico (negro/ } \\
\text { preto) } \\
\text { Casal heterossexual: o } \\
\text { homem performa drag } \\
\text { queen (branco) } \\
\text { Casal lésbico: mulher } \\
\text { transexual e mulher } \\
\text { heterossexual (branca)' }\end{array}$ \\
\hline
\end{tabular}

Fonte: Elaborado pelo autor (2020).

Consequentemente a esses arranjos, foram identificados seis novos filmes publicitários com o recorte de interesse da investigação em foco, sendo que cinco desses anúncios apresentavam casais LGBT negros ou inter-raciais em suas configurações. Os novos anúncios constam organizados no Quadro 2, que deve ser lido de modo integrado como o Quadro 1, tendo em vista que ambos formam o conjunto de anúncios utilizados para fomentar os diálogos edificados na etapa das entrevistas intensivas/em profundidade.

28. Disponível em: https://cutt.ly/efYj7cx. Acesso em: 10 ago. 2020.

29. Disponível em: https://cutt.ly/mfYj5SE. Acesso em: 10 ago. 2020.

30. Disponível em: https://cutt.ly/jfYj6Wd. Acesso em: 10 ago. 2020.

31. Disponível em: https://cutt.ly/tfYkqFU. Acesso em: 10 ago. 2020.

32. Disponível em: https://cutt.ly/kfYkwPC. Acesso em: 10 ago. 2020.

33. Disponível em: https://cutt.ly/7fYkezn. Acesso em: 10 ago. 2020.

34. Disponível em: https://cutt.ly/QfYkrbe. Acesso em: 10 ago. 2020.

35. Disponível em: https://cutt.ly/GfYktgX. Acesso em: 10 ago. 2020.

36. Disponível em: https://cutt.ly/3fYkydy. Acesso em: 10 ago. 2020.

37. Disponível em: https://cutt.ly/JfYky9o. Acesso em: 10 ago. 2020.

38. Disponível em: https://cutt.ly/9fYku9F. Acesso em: 10 ago. 2020. 
Com esse conjunto de anúncios atualizado e o referencial teórico do estudo suplementado, as atividades para o desenvolvimento da pesquisa seguiram de modo mais confortável. Novas entrevistas foram realizadas com a utilização também dos últimos anúncios identificados e não produziram dissonâncias. É interessante notar ainda que os novos anúncios, além de considerar casais LGBT negros, apresentam outras representações que também não constavam nos quadros dos anúncios da primeira fase, como um homem, aparentemente heterossexual, que performa uma drag queen e casais LGBT inter-raciais.

Os ajustes e as novidades inscritas no processo da pesquisa trouxeram equilíbrio para a etapa das entrevistas, e o desconforto com a ausência da representação de casais LGBT negros não foi mais expressado e percebido pelos agentes parentais informantes da investigação.

\section{CONSIDERAÇÕES FINAIS}

Neste artigo, buscou-se compartilhar algumas experiências, inquietações e deliberações metodológicas desenvolvidas ao longo do processo de uma investigação em grounded theory. Com as deliberações e tomadas de decisão realizadas frente aos desafios que emergiram na construção da pesquisa, observou-se um equilíbrio das vozes dos agentes parentais, tanto brancos e negros quanto homoafetivos e heteroafetivos, em relação às imagens representadas nos filmes publicitários contraintuitivos selecionados para fomentar as entrevistas em profundidade da pesquisa.

Espera-se que os cuidados adotados e apresentados neste artigo para aperfeiçoar o racional e os processos da pesquisa tenham sido úteis para demonstrar como as inquietações metodológicas podem ser observadas como oportunidades para aperfeiçoar os procedimentos e técnicas de pesquisa, de modo a torná-los mais comprometidos com o desenvolvimento dos saberes e ideias emergentes que enquadram pesquisas qualitativas.

\section{REFERÊNCIAS}

ABDO, S. Representatividade de LGBTs e deficientes não chega a 0,5\% dos comerciais no Brasil. O Estado de S. Paulo, São Paulo, 13 jan. 2018. Disponível em: https://bit.ly/2VkrCTE. Acesso em: 31 ago. 2020.

ADJEPONG, A. Invading ethnography: a queer of color reflexive practice. Ethnography, Thousand Oaks, v. 20, n 1, p. 27-46, 2019.

ALEXANDER, B. K. Queer/Quare theory: worldmaking and methodologies. In: DENZIN, N. K.; LINCOLN, Y. S. (ed.). The SAGE Handbook of Qualitative Research. $5^{\text {th }}$. ed. Thousand Oaks: Sage, 2018.

ANZALDÚA, G. (ed.) Making face, making soul/haciendo caras: creative and critical perspectives by feminists of color. San Francisco: Aunt Lute Books, 1990.

BAGGIO, A. T. A temática homossexual na publicidade de massa para público gay e não-gay: conflito entre representação e estereótipo. Revista Uninter de Comunicação, Curitiba, v. 1, n. 1, p. 100-117, 2013.

BAGGIO, A. T. A temática homossexual na publicidade: representação e estereótipos In: CONGRESSO BRASILEIRO DE CIÊNCIAS DA COMUNICAÇ̃̃O, 32., 2009, Curitiba. Anais [...]. São Paulo: Intercom, 2009. p. 1-15.

BAUDRILLARD, J. O sistema dos objetos. São Paulo: Perspectiva, 1973.

BLAIR, I. V.; MA, J. E.; LENTON, A. P. Imagining stereotypes away: the moderation of 
implicit stereotypes through mental imagery. Journal of Personality and Social Psychology, Washington, DC, v. 81, n. 5, p. 828-841, 2001

BLAIR, V. I.; BANAJI, M. R. Automatic controlled processes in stereotyping priming. Journal of Personality and Social Psychology, Washington, DC, v. 70, n. 6, p. 1142-1163, 1996.

BOLDRINI, A. Brancos ainda são 78\% dos representados em anúncios. Folha de S.Paulo, São Paulo, 16 fev. 2020. Disponível em: https://bit.ly/37nVyE4. Acesso em: 31 ago. 2020

BOURDIEU, P. A dominação masculina. Rio de Janeiro: Bertrand Brasil, 1999.

BOYER, P. Religion explained: the evolutionary origins of religious thought. New York: Basic Books, 2001.

BROCKENBROUGH, E. Queer of color agency in educational contexts: analytic frameworks from a queer of color critique. Educationa/ Studies, Abingdon, v. 51, n. 1, p. 28-44, 2015

CHARMAZ, K. A construção da teoria fundamentada: guia prático para análise qualitativa. Tradução de Joice Elias Costa. Porto Alegre: Artmed, 2009.

CHARMAZ, K. Constructing Grounded Theory: a practical guide through qualitative analysis. 2. ed. London: Sage, 2014.

CHIARELLI JR., M.; MACEDO, D. A publicidade como reflexo da sociedade - análise sobre o filme publicitário dia dos namorados de O Boticário 2015. In: CONGRESSO DE CIÊNCIAS DA COMUNICAÇÃO NA REGIÃO SUL, 17., 2016, Curitiba. Anais [...]. São Paulo: Intercom, 2016. p. 1-13.

COLLINS, J. C.; TABORDA-WHITT, C. Disrupting human resource development to see, hear, and value queer people of color: a call to action. New Horizons in Adult Education \& Human Resource Development, Hoboken, v. 29, n. 1, p. 1-4, 2017.

COLLINS, P. H. Pensamento feminista negro: conhecimento, consciência e a política do conhecimento. Tradução de Jamile Pinheiro Dias. São Paulo: Boitempo, 2019.

COLLINS, P. H. Se perdeu na tradução? Feminismo negro, interseccionalidade e política emancipatória. Parágrafo, São Paulo, v. 5, n. 1, p. 6-17, 2017.

CRENSHAW, K. Demarginalizing the intersection of race and sex: A black feminist critique of antidiscrimination doctrine, feminist theory, and antiracist politics. University of Chicago Legal Forum, Chicago, v. 1989, n. 1, p. 139-167, 1989.

CRENSHAW, K. Documento para o encontro de especialistas em aspectos da discriminação racial relativos ao gênero. Estudos Feministas, Florianópolis, v. 10, n. 1, p. 171-188, 2002.

CRUZ, D. E. T. C.; VILLEGAS G. M. L. G. C. A publicidade utilizada como elemento retórico para a desconstrução de preconceitos na sociedade. In: ENCONTRO NACIONAL DE PESQUISADORES EM PUBLICIDADE E PROPAGANDA, 7., 2016, Rio de Janeiro. Anais [...]. São Paulo: INMOD/ABP2, 2016. p. 11106-1119.

DALTRO, M. R.; FARIA, A. A. Relato de experiência: uma narrativa científica na pós-modernidade. Estudos e Pesquisas em Psicologia, Rio de Janeiro, v. 19, n. 1, p. 223-237, 2019.

DASGUPTA, N.; GREENWALD, A. G. On the malleability of automatic attitudes: combating automatic prejudice with images of admired and disliked individuals. Journal of Personality and Social Psychology, Washington, DC, v. 81, n. 5, p. 800-814, 2001.

DI NALLO, E. Meeting points. Soluções de Marketing para uma sociedade complexa. São Paulo: Cobra, 1999.

DIAS, M. B. União homossexual, o preconceito e a justiça. 3. ed. Porto Alegre: Livraria do Advogado, 2005.

DIAS, M. B. Família homoafetiva. Bagoas, Natal, v. 2, n. 3, p. 39-63, 2012.

FERGUSON, R. Aberrations in black: toward a queer of color critique. Minneapolis: University of Minnesota Press, 2004.

FERNANDES, E.; MAIA, A. Grounded Theory. In: FERNANDES, E. M.; ALMEIDA, L. S. (ed.). Métodos e técnicas de avaliação: contributos para a prática e investigação psicológicas. Braga: Universidade do Minho, 2001. p. 46-76.

FRANÇA, M. R. C. Famílias homoafetivas. Revista Brasileira de Psicodrama, São Paulo, v. 17, n. 1, p. 21-33, 2009. 
GARCÍA CANCLINI, N. Consumidores e cidadãos: conflitos multiculturais da globalização. Rio de Janeiro: Editora UFRJ, 1995.

GLASER, B.; STRAUSS, A. The discovery of grounded theory: strategies for qualitative research. Chicago; New York: Aldine de Gruyter, 1967.

GOPINATH, G. Impossible desires: queer diasporas and South Asian public cultures. Durham: Duke University Press, 2005.

GUIMARÃES, A. S. A. Raça, cor, cor da pele e etnia. Cadernos de Campo, São Paulo, n. 20, v. 20, p. 265-271, 2011.

INFANTE, L. Apesar de evolução, publicidade ainda reforça estereótipos sobre a população negra, aponta estudo. Época, São Paulo, 7 jan. 2019. Disponível em: https://glo.bo/37fmm9e. Acesso em: 31 ago. 2020.

IRIBURE, A. A única tonalidade negra das representações LGBTQIA+ na publicidade em TV aberta e sua repercussão no Facebook. In: TEIXEIRA FILHO, C. (org.) Reflexões sobre comunicação e diversidade sexual e de gênero. Londrina: Syntagma Editores, 2018.

IRIBURE, A. As representações das homossexualidades na publicidade e propaganda veiculadas na televisão brasileira: um olhar contemporâneo das últimas três décadas. Tese (Doutorado em Comunicação e Informação) - Faculdade de Biblioteconomia e Comunicação, Universidade Federal do Rio Grande do Sul, Porto Alegre, 2008.

IRIBURE, A. Entre as representações e as repercussões das homossexualidades: uma análise da publicidade veiculada na TV aberta e seus desdobramentos na rede social. In: ENCONTRO NACIONAL DE PESQUISADORES EM PUBLICIDADE E PROPAGANDA, 7. 2016, Rio de Janeiro. Anais [...]. São Paulo: INMOD/ABP2, 2018. p. 136-155.

IRIBURE, A. Parte 2 - Quase homem, quase mulher: as repercussões na rede social Facebook de gênero e sexualidade trans da publicidade veiculada na televisão aberta brasileira. In: CONGRESSO BRASILEIRO DE CIÊNCIAS DA COMUNICAÇÃO, 41., 2019, Joinville. Anais [...]. São Paulo: Intercom, 2018. p. 1-15.

IRIBURE, A.; CARVALHO, A. Desde a década de setenta, em setenta comerciais: as representações LGBT na publicidade e propaganda veiculadas na televisão brasileira. In: ENCONTRO NACIONAL DE HISTÓRIA DA MÍDIA, 10., 2015, Porto Alegre. Anais [...]. Porto Alegre: UFRGS, 2015. n. p.

JOHNSON, D. D. Black queer identity Matrix: towards an integrated queer of color framework (review). QED: A Journal in GLBTQ Worldmaking, East Lansing, v. 2, n. 2, p. 230-233, 2015.

LEAL, J. T. B. Advergay: do armário ao comercial de O Boticário. Revista Espaço AcadêmiCo, Maringá, v. 16, n. 187, p. 35-47, 2016.

LEAL, J. T. B. Advergay: uma ação publicitária "no armário", "in Box" ou "publicidade-michê"?. 2013. Dissertação (Mestrado em Comunicação) - Pontifícia Universidade Católica do Rio de Janeiro, Rio de Janeiro, 2013

LEITE, F. A informação como suporte para a publicidade contra-intuitiva. Animus - Revista Interamericana de Comunicação Midiática, Santa Maria, v. 6, n. 2, p. 151-171, 2007.

LEITE, F. As brasileiras e a publicidade contraintuitiva: enfrentamento do racismo pela midiatização da imagem de mulheres negras. São Paulo: Alameda, 2018

LEITE, F. Raciocínio e procedimentos da Grounded Theory Construtivista. Questões Transversais - Revista de Epistemologias da Comunicação, São Leopoldo, v. 3, n. 6, p. $76-85,2015$

LEITE, F., BATISTA, L. L. (org). Publicidade antirracista: reflexões, caminhos e desafios. São Paulo: ECA-USP, 2019

LEITE, F.; BATISTA, L. L. Primeiras Experiências com o racismo: crianças negras, práticas parentais e midiatização. São Paulo: Annablume, 2018.

LOPES, D. Desafios dos estudos gays, lésbicos e transgêneros. Comunicação, Mídia e Consumo, São Paulo, v. 1, n. 1, p. 63-73, 2004

LORDE, A. The marvelous arithmetics of distance. New York: W.W. Norton \& Co., 1994.

MANALANSAN IV, M. F. Messing up sex: the promises and possibilities of queer of color critique. Sexualities, Thousand Oaks, v. 21, n. 8, p. 1287-1290, 2018. 
MENDES, J. M. Entre dinâmicas de mercado e identitárias: os youtubers e a controvérsia publicitária d’O Boticário. ENCONTRO ANUAL DA COMPÓS, 26., 2017, São Paulo. Anais [...]. Belo Horizonte: Compós, 2017.

MISKOLCI, R. Teoria Queer: um aprendizado pelas diferenças. 3. ed. Belo Horizonte: Autêntica, 2017.

MOCH, S. D.; GATES, M. F. (ed.). The Researcher Experience in Qualitative Research. London: Sage, 2000.

MOZDZENSKI, L.; SILVA, K. C. A publicidade brasileira está saindo do armário? análise crítica de filmes publicitários do Dia dos Namorados. In: CONGRESSO BRASILEIRO DE CIÊNCIAS DA COMUNICAÇÃO, 39., 2016, São Paulo. Anais [...]. São Paulo: Intercom, 2016. p. 1-15.

MULATINHO, J. I. M.; BEZERRA, J. S. Propaganda e Representatividade: análise do discurso publicitário em uma nova conjuntura social. In: CONGRESSO BRASILEIRO DE CIÊNCIAS DA COMUNICAÇÃO, 39., 2016, São Paulo. Anais [...]. São Paulo: Intercom, 2016. p. 1-15.

NEGROS ainda são minoria em peças publicitárias nas redes sociais. Meio \& Mensagem, São Paulo, 16 jun. 2020. Disponível em: https://bit.ly/3ocTwxs. Acesso em: 31 ago. 2020.

OLIVEIRA, J. A. A publicidade rende-se à diversidade sexual: um estudo de recepção sobre a campanha 'Casais' do perfume Egeo de O Boticário. In: CONGRESSO BRASILEIRO DE CIÊNCIAS DA COMUNICAÇÃO, 38., 2015, Rio de Janeiro. Anais [...]. São Paulo: Intercom, 2015. p. 1-14.

OLIVEIRA, J. A. Publicidade e diversidade sexual na campanha 'Casais' do perfume Egeo de O Boticário. Revista Tecer, Belo Horizonte, v. 9, n. 17, p. 95-105, 2016.

ORLANDI, E. P. As formas do silêncio: no movimento dos sentidos. Campinas: Editora Unicamp, 1995.

PIEDRAS, E. R. As práticas de recepção da publicidade como fluxo: apontamentos teóricos-metodológicos. Contemporânea, Salvador, v. 5, n. 1-2, p. 1-18, 2007.

PIZA, E.; ROSEMBERG, F. Cor nos censos brasileiros. Revista USP, São Paulo, n. 40, p. 122-137, 1999.

REDDY C. Freedom with violence: race, sexuality, and the US State. Durham:

Duke University Press, 2011.

REINO, L. S. S.; CARVALHO, C. M. As sutis tentações: análise do vídeo publicitário O Dia dos Namorados da marca O Boticário. In: CONGRESSO BRASILEIRO DE CIÊNCIAS DA COMUNICAÇÃO, 38., 2015, Rio de Janeiro. Anais [...]. São Paulo: Intercom, 2015. p. 1-11.

ROCHA, E. Magia e Capitalismo: um estudo antropológico da publicidade. São Paulo: Brasiliense, 2010.

RUAN, E.; KNOBBE, M. M. A Publicidade Colorida: Considerando Justa "Toda Forma de Amor”. In: CONGRESSO BRASILEIRO DE CIÊNCIAS DA COMUNICAÇ̃̃O, 39., 2016, São Paulo. Anais [...]. São Paulo: Intercom, 2016. p. 1-13.

SANTOS, J. V. T. A violência simbólica: o Estado e as práticas sociais. Revista Crítica de Ciências Sociais, Coimbra, v. 108, p. 189-190, 2015.

SANTOS, M. O.; MARMITT, G. Me representa ou não me representa: percepções de um público LGB sobre as representações das homossexualidades na publicidade da TV aberta brasileira. In: CONGRESSO BRASILEIRO DE CIÊNCIAS DA COMUNICAÇÃO, 40., 2017, Curitiba. Anais [...]. São Paulo: Intercom, 2017. p. 1-15.

SILVA, A. H. M.; HANSEN, F. As diferentes representações nas narrativas publicitárias do mês do orgulho de 2018. In: ENCONTRO NACIONAL DE PESQUISADORES EM PUBLICIDADE E PROPAGANDA, 10., 2019, São Paulo. Anais [...]. São Paulo: ECA-USP, 2020. P. 1541-1554.

SILVA, D. T.; LAHNI, C. R. Toda forma de amor: publicidade, consumo e cidadania. Revista Passagens, Fortaleza, v. 6, n. 2, p. 146-164, 2015.

SILVA, R. A. V. Propaganda e diversidade: mudanças de paradigma no contexto de inclusão da diversidade na mensagem publicitária brasileira. In: CONGRESSO BRASILEIRO DE CIÊNCIAS DA COMUNICAÇÃO, 39., 2016, São Paulo. Anais [...]. São Paulo: Intercom, w2016. p. 1-15.

SMITH, L. T. Decolonizing methodologies: research and indigenous peoples. New York: St. Martin's Press, 1999. 
SOMERVILLE, S. B. Queering the color line: race and the invention of homosexuality in America. Durham: Duke University Press, 2000.

SPADIN, A. C. R. As marcas e o consumidor: um estudo dos discursos da publicidade na perspectiva da modificação dos estereótipos na representação da família. 2016. Dissertação (Mestrado) - Escola de Comunicação, Educação e Humanidades da Universidade Metodista de São Paulo, São Bernardo do Campo, 2015.

STRAUSS, A.; CORBIN, J. Pesquisa qualitativa: técnicas e procedimentos para o desenvolvimento de teoria fundamentada. Tradução de Luciane de Oliveira da Rocha. 2. ed. Porto Alegre: Artmed, 2008.

TAROZZI, M. O que é grounded theory? Metodologia de pesquisa e de teoria fundamentada nos dados. Tradução de Carmen Lussi. Petrópolis: Vozes, 2011.

TRINDADE, E. Recepção publicitária e práticas de consumo. Fronteiras, São Leopoldo, v. 10, n. 2, p. 73-80, 2008.

UPAL, M. A. What is more memorable counterintuitive concepts interpreted metaphorically or literally?. In: ANNUAL MEETING OF THE COGNITIVE SCIENCE SOCIETY, 29., 2007, Nashville. Proceedings [...]. Austin: Cognitive Science Society, 2007. p. 1581-1586. 